\title{
FLOATING VETIVER ISLAND (FVI) AND IMPLICATION FOR TREATMENT SYSTEM DESIGN OF POLLUTED RUNNING WATER
}

\author{
Kusin, F. M. ${ }^{1,2^{*}}-$ HASAN, S. N. M. S. ${ }^{1}-$ NORdin, N. A. ${ }^{1}-$ MOHAMAT-YUSUFF, F. ${ }^{1,2}-$ \\ IBRAHIM, Z. Z. ${ }^{1}$ \\ ${ }^{I}$ Department of Environmental Sciences, Faculty of Environmental Studies, Universiti Putra \\ Malaysia, 43400 UPM Serdang, Selangor, Malaysia \\ ${ }^{2}$ Environmental Forensics Research Unit, Faculty of Environmental Studies, Universiti Putra \\ Malaysia, 43400 UPM Serdang, Selangor, Malaysia \\ *Corresponding author \\ e-mail: faradiella@upm.edu.my; phone: +60-10-366-6160; fax: +60-38-946-7463
}

(Received $8^{\text {th }}$ Aug 2018; accepted $5^{\text {th }}$ Oct 2018)

\begin{abstract}
Floating Vetiver Island (FVI) system has been investigated in this study as a relatively new technology of artificial wetland treatment. Vetiver grass (Vetiveria zizanioides) was used as the treatment vegetation in the FVI owing to its high tolerance to various types of contaminants. Performance of the FVI was tested on actual polluted running water having characterized by a Class III-Class IV river according to water quality index (WQI) classification. Field trial of FVI over a six-week installation demonstrated an improved water quality with significant increase $(92 \%)$ of dissolved oxygen and great removals of chemical oxygen demand $(77 \%)$ and nitrate $(73 \%)$, resulting in $14 \%$ increase of the overall WQI. It was proposed that treatment system performance for FVI can be reflected by the number of pontoons (FVIs) and treatment distance required to achieve desired water quality improvement. The calculated pollutant removal rates were incorporated into the estimation of treatment system requirements. Field installation guide for FVI system is also presented along with treatment system maintenance. For such an FVI system, vetiver grass pruning (trimming) at 2-month intervals is recommended for promoting the growth of the plant and for medium- to long-term FVI performance.

Keywords: pontoons, water quality, treatment design, vetiver grass, pollutant removal
\end{abstract}

\section{Introduction}

Previous researches have discovered various kinds of artificial wetland treatment systems using plants which are adopted to treat contaminated water such as artificial floating island (AFI), floating treatment wetland (FTW), conventional constructed wetland $(\mathrm{CW})$, floating plant bed system, integrated floating system, integrated ecological floating bed (IEFB) and etc. (Yao et al., 2011; Zhao et al., 2012; Kusin et al., 2014; Chang et al., 2015; Lu et al., 2015; Lynch et al., 2015; Yeh et al., 2015). These artificial wetland treatment technologies produce similar function which is generally for water quality improvement. In this study, floating vetiver island (FVI) using vetiver grass (VG) has been designed and tested for field trial due to high tolerance of VG for contaminant removal in treating polluted water. Vetiver grass (Vetiveria zizanioides) has outstanding physiological and morphological features and it is economical and effective in removing pollutants from water (Truong, 2000; Danh et al., 2009; Darajeh et al., 2014; Suelee et al., 2017). Vetiver grass has been used in various water and wastewater treatment applications such as for stormwater, domestic and industrial wastewater treatment including palm oil mill effluent, sewage and mine tailings (Xia et 
al., 2000; Shu et al., 2002; Ash and Truong, 2003; Shu and Xia, 2003; Roongtanakiat et al., 2007; Darajeh et al., 2014).

Generally, the removal of pollutants within a floating island system occurs as water passes beneath the floating mat which include uptake of metals and nutrients, contaminant clearing and binding as well as flocculation enrichment of suspended matter by plant roots (Yeh et al., 2015). In most instances, floating island system has been mainly used for purification of polluted water due to its proficiency in removing excess amount of nutrient contents. For instance, application of AFI contributed to reduction in nutrient level such as nitrate, potassium, ammoniacal nitrogen and total suspended solids as a result of nutrient and organic constituent uptakes by plant species which results in alteration of river water quality (Yao et al., 2011; Yeh et al., 2015). Other studies revealed that FTW is significant in removing $10,600 \mathrm{mg}$ of nitrate $(\mathrm{N})$, $428 \mathrm{mg}$ of phosphate (P) and $273 \mathrm{mg}$ of ammonium (AN) per day (Zhang et al., 2015), whilst removals of chemical oxygen demand (COD), total nitrogen (TN) and total phosphorus (TP) are between (24.5\% to $37.6 \%)$, (34\% to $42 \%)$ and $(36.1 \%$ to $81.4 \%)$ respectively (Lu et al., 2015). In an example of a polluted river, removal of TN and $\mathrm{P}$ was $34 \%$ and $68.1 \%$, respectively after one week of floating system installation and nutrient removal continues to increase up to $99 \%$ for $\mathrm{P}$ after three weeks and $82 \%$ for TN after four weeks (Zhao et al., 2012). However, despite being known that floating island system can be a reliable technology in water purification, the challenges remain that of full-scale implementation requirements and selection of appropriate treatment system for site-specific cases.

Notwithstanding this, most of previous studies with regard artificial floating wetland technology have been focusing on the application of such system for treatment of standing or stagnant water such as wetlands, lakes, ponds and on-site drainages (Yeh et al., 2015). However, in this study the FVI system is applied for treatment of polluted running water (i. e. river, stream or canal), which has never been investigated of its potential use. In Malaysia, river water is the main source of raw water and has been extensively used for domestic and agricultural purposes, industrial uses, generation of hydroelectric power, irrigation and other functions within a watershed (Chan, 2012; Othman et al., 2012; Al-Badaii et al., 2013; Cleophas et al., 2013; Kusin et al., 2016). Nevertheless, river water pollution has become a major environmental issue due to various anthropogenic activities from rapid urbanization and inappropriate management attempts (Fulazzaky et al., 2010; Biswas and Tortajada, 2011; Chan, 2012). As a consequence, discharges of several types of pollutants have contaminated the river as well as affecting aquatic organisms. Deteriorating river water quality in Malaysia particularly in the state of Selangor and Federal Territory of Kuala Lumpur has pointed out that attention is needed to treat our rivers for water sustainability in the future (Kusin et al., 2016). Therefore, a potential water treatment system is proposed in this study to purify polluted river to at least achieve a Class II river as required by relevant Malaysian water authorities.

Thus, the objectives of this study are to evaluate pollutant removal efficiency using FVI system in running water for improvement of river water quality and to develop a guideline for FVI design, field installation and estimation of treatment requirements for running water. Performance of the FVI was tested in actual river water and was evaluated of its potential application. 


\section{Materials and methods}

\section{Study site}

A pilot test for assessing treatment efficiency of FVI was performed on actual river water. The river is a relatively small channel with approximately $3 \mathrm{~m}$ wide, $0.5 \mathrm{~m}$ deep and has flow rate of $0.1 \mathrm{~m}^{3} / \mathrm{s}$. It receives domestic discharges within a university campus and nearby residential area having characterized by a Class III-Class IV water based on Water Quality Index (DOE-WQI) classification (Fig. 1).

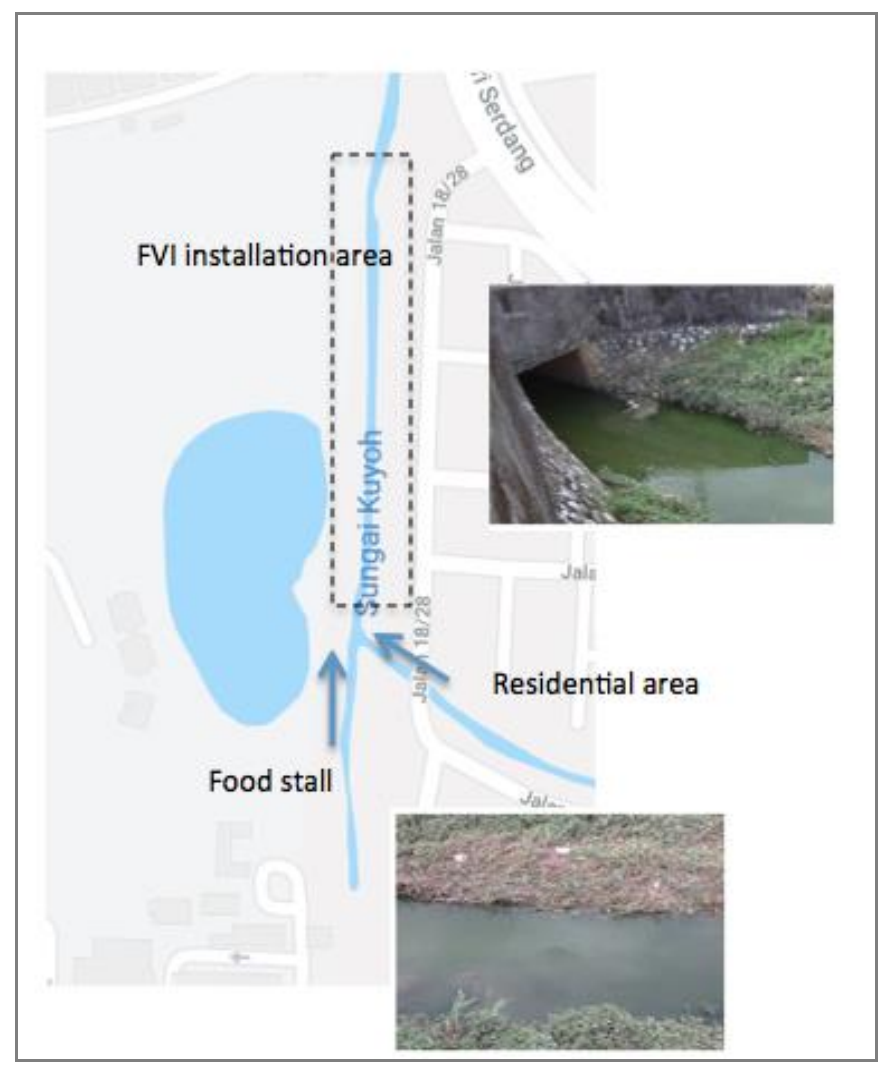

Figure 1. Location of study area

\section{Field deployment of floating vetiver island (FVI)}

The FVI was designed for a relatively small river or channel. Fabrication of FVI included the fabrication of floating island mat and VG planting inside the FVI. The FVI were made up of $1 \mathrm{~m} \times 1 \mathrm{~m}$ uPVC pipes and synthetic net and were tied using steel band with bolt and nuts so that the net can hold the plants more appropriately (Fig. 2). After fabrication, VGs were planted on the floating mat at an amount of 100 tillers per FVI whereby four young tillers were grouped and tied together on the synthetic net to prevent breaking up of the young roots and soils. This was also to avoid VGs from being easily washed away in case of strong river flow (Fig. 3a). The VGs were planted evenly over the surface of the FVI to ensure its stability during installation and were placed in water for the growth of the root. Field deployment of FVI was performed through installation of nine FVIs within a distance of $500 \mathrm{~m}$ and with different arrangement patterns such as row and diamond planting (Fig. 3b). Measured variables for water quality were monitored in six weeks for physicochemical parameters $(\mathrm{pH}$, 
temperature, dissolved oxygen (DO), conductivity, total dissolved solids (TDS), turbidity), BOD, COD, TSS, and nutrient contents (nitrate $(\mathrm{N})$, phosphate $(\mathrm{P})$, ammoniacal nitrogen (AN)).

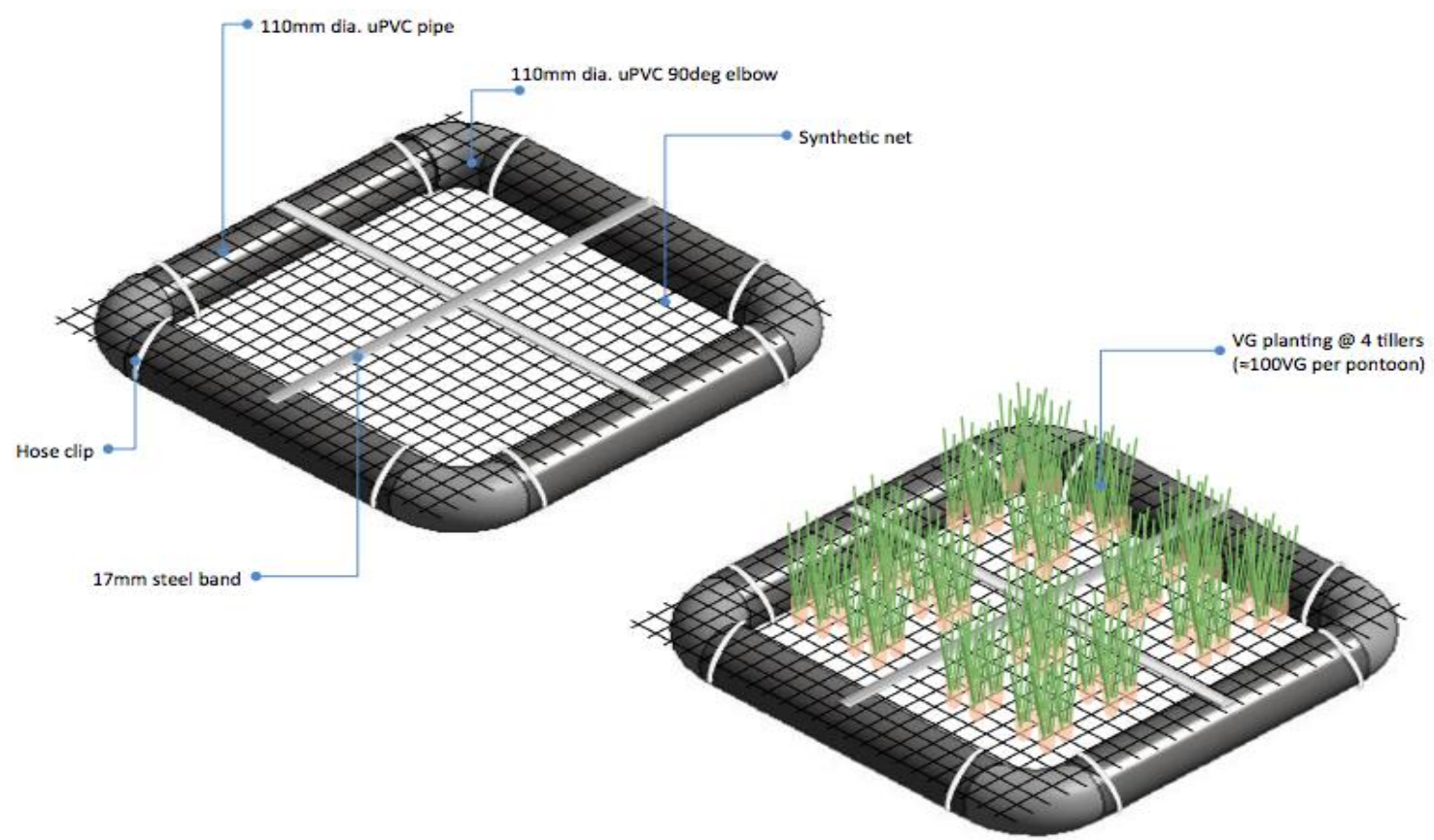

Figure 2. FVI design of $1 \mathrm{~m} \times 1 \mathrm{~m}$ in size

\section{Field measurement, sampling and analysis}

Measurements of water physicochemical parameters $(\mathrm{pH}$, conductivity, TDS and temperature) were taken using a calibrated Myron L Ultrameter 6P. Turbidity was measured using an Orion Aquafast turbidity meter, while dissolved oxygen was measured using a DO meter. Samples of water for analysis of BOD, COD, TSS, AN, N and $\mathrm{P}$ were taken in 1-L polyethylene bottles and were brought back to laboratory for analysis. Laboratory analysis of BOD, COD, TSS, AN, N and P, and the sample preservation were carried out according to standard methods for the examination of water and wastewater (APHA, 2005). Water velocity and water depth were measured using a flow meter with an impeller and were incorporated into the calculation of water flow rate using velocity-area method (Kusin et al., 2012). Sampling and water quality measurements were undertaken on weekly basis (three times a week) at a point before and after the installation of FVI. The water samples were collected at a depth of between $15-20 \mathrm{~cm}$ from the surface.

\section{Data analysis}

All six water quality parameters $(\mathrm{pH}, \mathrm{DO}, \mathrm{TSS}, \mathrm{BOD}, \mathrm{COD}, \mathrm{AN})$ required in calculating Water Quality Index (WQI) were determined on-site and also in laboratory. Results obtained were compared with National Water Quality Standards for Malaysia (NWQS) and Malaysian Department of Environment Water Quality Index classification (DOE-WQI) (Table 1). The WQI was calculated using Equation 1 as follows (DOE, 2010): 


$$
\mathrm{WQI}=0.22 \mathrm{SIDO}+0.19 \mathrm{SIBOD}+0.16 \mathrm{SICOD}+0.15 \mathrm{SIAN}+0.16 \mathrm{SISS}+0.12 \mathrm{SIpH} \quad(\text { Eq. } 1)
$$

where SI is the sub-index of each parameters and were obtained from a series of equations.

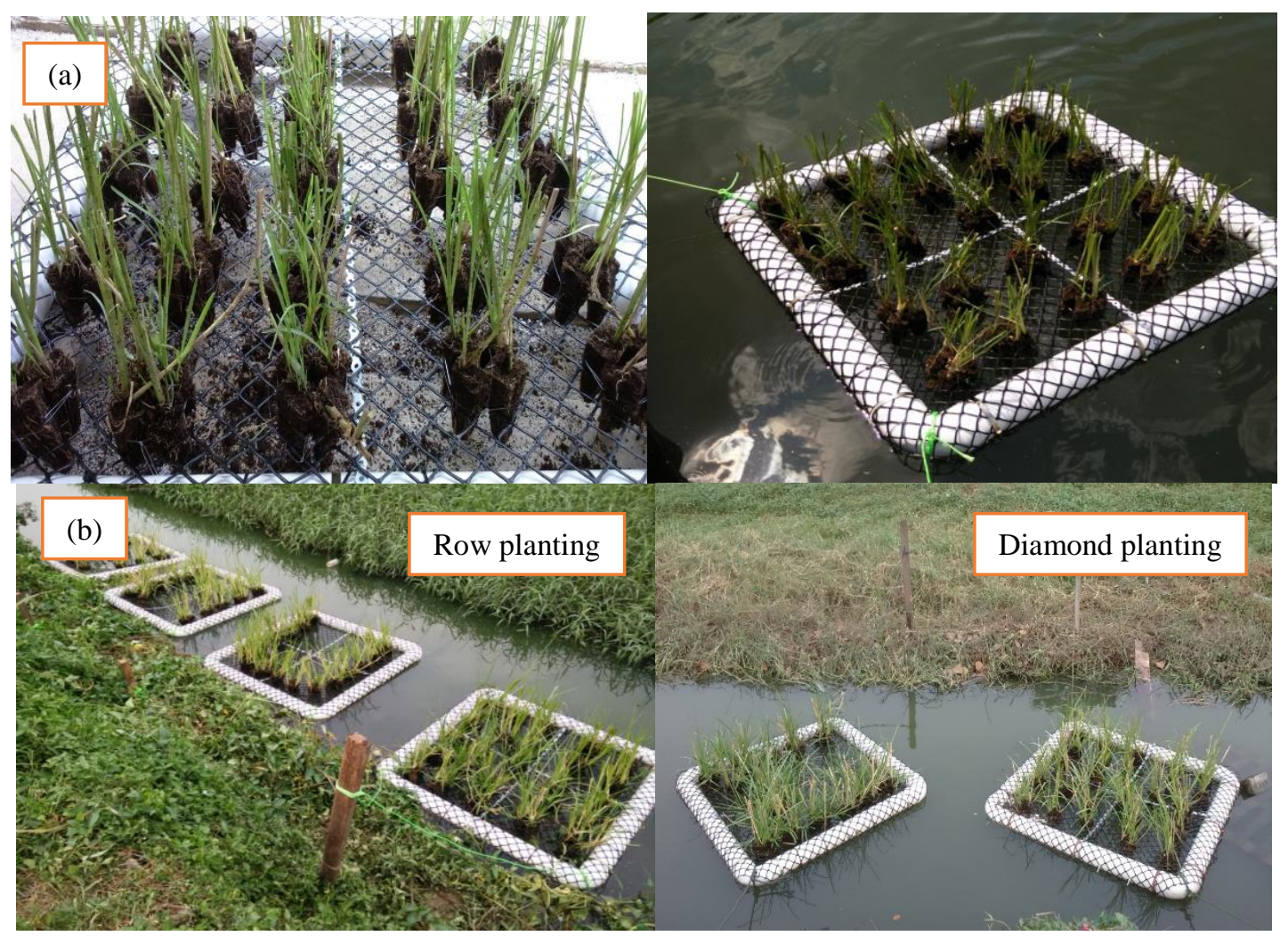

Figure 3. (a) VG planting in the FVI (b) field installation of FVI at site

Table 1. Water quality classification of selected parameters according to National Water Quality Standards (NWQS) for Malaysia (DOE, 2008)

\begin{tabular}{llllllll}
\hline Parameter & \multicolumn{2}{c}{ Class } & & & & & \\
\cline { 2 - 8 } & Unit & I & IIA & IIB & III & IV & V \\
\hline pH & & $6.5-8.5$ & $6-9$ & $6-9$ & $5-9$ & $5-9$ & - \\
DO & $\mathrm{mg} / \mathrm{L}$ & 7 & $5-7$ & $5-7$ & $3-5$ & $<3$ & $<1$ \\
BOD & $\mathrm{mg} / \mathrm{L}$ & 1 & 3 & 3 & 6 & 12 & $>12$ \\
$\mathrm{COD}$ & $\mathrm{mg} / \mathrm{L}$ & 10 & 25 & 25 & 50 & 100 & $>100$ \\
$\mathrm{TSS}$ & $\mathrm{mg} / \mathrm{L}$ & 25 & 50 & 50 & 150 & 300 & 300 \\
$\mathrm{AN}$ & $\mathrm{mg} / \mathrm{L}$ & 0.1 & 0.3 & 0.3 & 0.9 & 2.7 & $>2.7$ \\
\hline
\end{tabular}

Class I

Conservation of natural environment

Water supply I - Practically no treatment necessary

Fishery I - Very sensitive aquatic species

Class IIA

Water supply II - Conventional treatment required

Fishery II - Sensitive aquatic species

Class IIB Recreational use with body contact

Class III Water supply III - Extensive treatment required

Fishery III - Common of economic value and tolerant species; livestock drinking

Class IV Irrigation

Class V None of the above 


\section{Statistical analysis}

Statistical analysis was performed using SPSS statistical package software version 21. A one-way analysis of variance (ANOVA) was conducted to evaluate the variation in parameter improvement between weeks of observation. Subsequently, a Tukey HSD test was performed for multiple comparison between groups. Statistically significant differences were tested at $\mathrm{p} \leq 0.05$.

\section{Results and discussion}

\section{Water quality improvement}

General trend shows that improvement of water quality was observed throughout field deployment of FVI in the river, whereby the weekly changes of the observed parameters were found to be significantly changing $(\mathrm{p}<0.05)$. Results have demonstrated the increase of DO level by $92 \%$ (difference from initial value was significant, $\mathrm{p}<0.05$ ), which was in Class III, while $\mathrm{pH}$ was maintained at circumneutral range within six weeks of FVI installation (Fig. 4). DO is an important water quality parameter whereby the high DO level in contaminated water indicates that high amount of oxygen is accessible for the survival of $\mathrm{VG}$ and aquatic organisms (Yeh et al., 2015; Zhang et al., 2015). Therefore, application of the FVI has helped in significant increase of $\mathrm{DO}$ thus maintaining $\mathrm{pH}$ at reasonably good level.

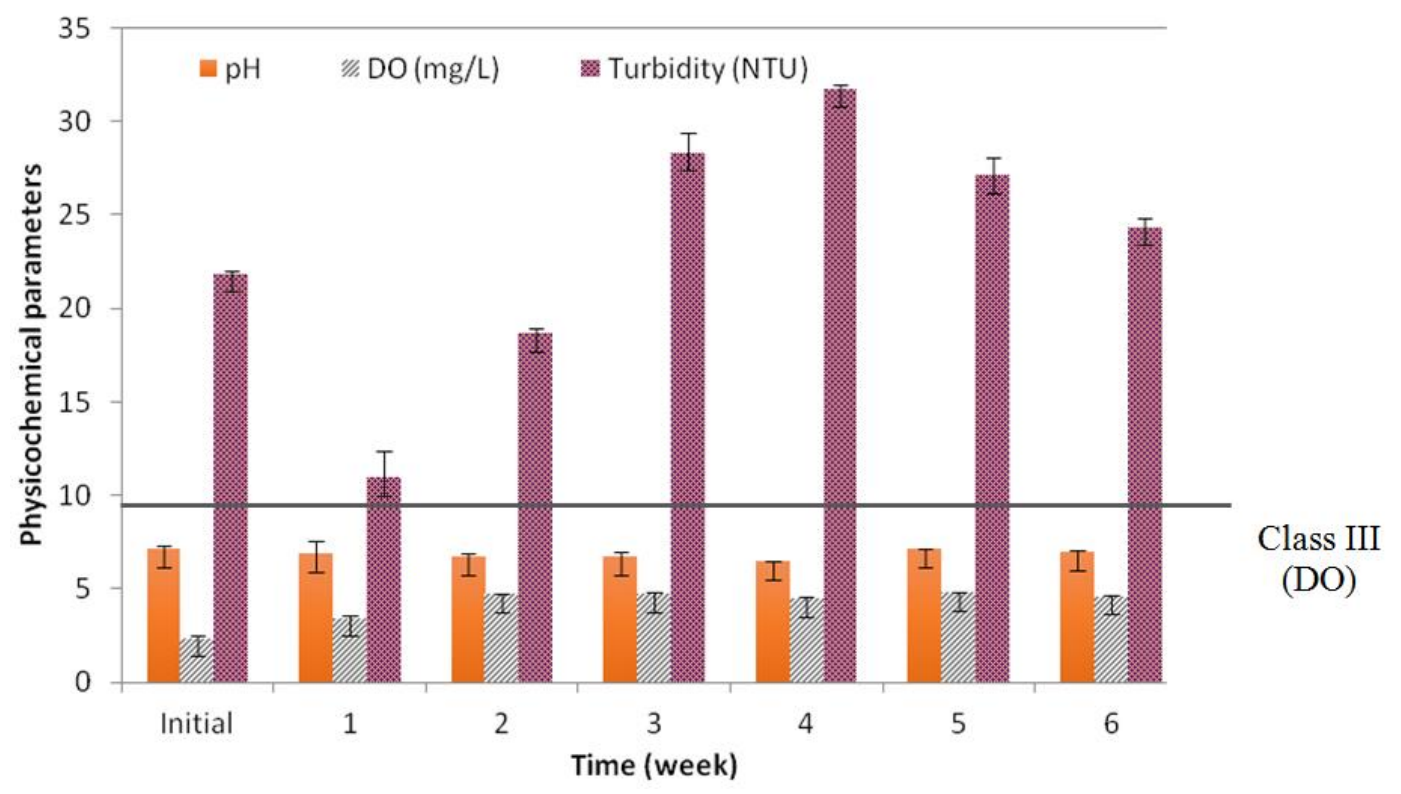

Figure 4. Weekly changes of physicochemical parameters in water after FVI installation

On the other hand, TSS and COD were found significantly decreased $(\mathrm{p}<0.05)$ over the installation period (Fig. 5), where COD recorded $77 \%$ removal in six weeks. Reduction of COD shows that decomposition of organic matter and oxidation of inorganic chemicals such as nitrate and ammonia in water consume less oxygen, which results in adequate oxygen left to support aquatic organisms (Lu et al., 2015). It has been noted that higher removal of organic constituents was due to higher uptake of 
contaminants by plant roots and consequently can improve river water quality (Yao et al., 2011; Yeh et al., 2015). Furthermore, fine massive VG root system enhances pollutant removal, which acts as an effective biofilter in trapping both fine and coarse sediment in running water (Truong and Smeal, 2003). This shows that vetiver root has a potential in removing organic constituents in water such as indicated by the amount of TSS, BOD and COD (Xia et al., 2000; Shu, 2003; Darajeh et al., 2014; Zhang et al., 2015).

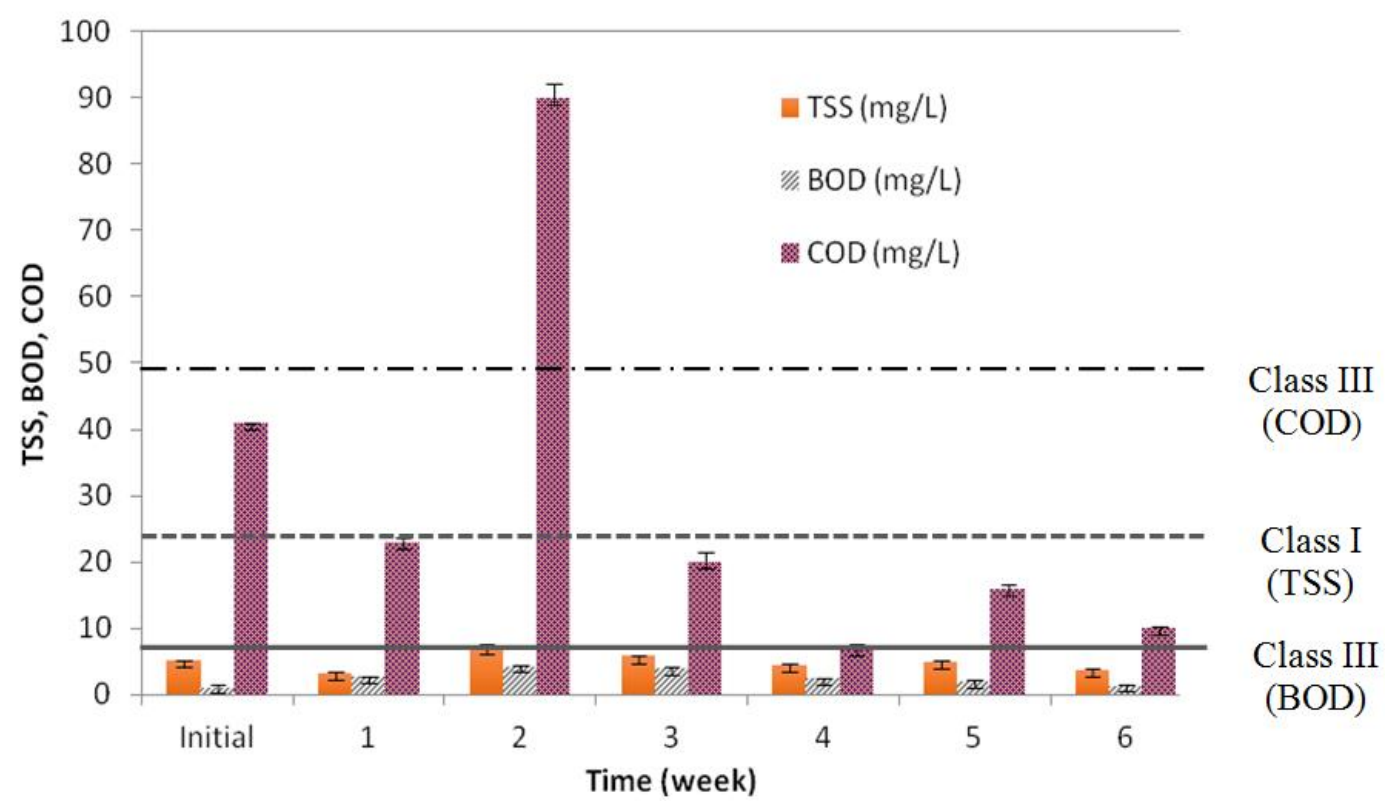

Figure 5. Weekly changes of TSS, BOD and COD of water after FVI installation

Generally, VG plays an important function for nutrient removal by a FVI system in contaminated water. Current findings show that nutrient contents in polluted river, in particular $\mathrm{N}, \mathrm{P}$ and $\mathrm{AN}$ were also found to be significantly decreased (Fig. 6). N recorded the highest removal up to $73 \%$, while AN and $\mathrm{P}$ showed some reductions, although still persisted at class IV in one month. The findings was in line with previous studies that application of floating islands planted with vegetation indicated high removal of $\mathrm{N}$ and $\mathrm{P}$ in contaminated water (Xia et al., 2000; Shu, 2003; Yao et al., 2011; Darajeh et al., 2014; Yeh et al., 2015). This is because of stronger absorption of nutrients by vetiver roots for plant growth, which results in higher nutrient removal in water (Truong and Hart, 2001). Notwithstanding this, excess amount of $\mathrm{N}$ and $\mathrm{P}$ in water bodies may trigger serious pollutants which can cause algal bloom as phytoplankton consume $\mathrm{N}$ as their main nutrients (Zhao et al., 2012; Yeh et al., 2015; Zhang et al., 2015). Therefore, removal of nutrient contents by the plants can avoid water eutrophication as well as improving the quality of polluted river. In general, findings suggested that application of FVI has a potential in the purification of the river water especially in removing nitrate and COD, and increasing DO level. Overall, the WQI showed 14\% improvement (difference from initial value was significant, $\mathrm{p}<0.05$ ) after the six-week installation of FVI, although still remained at Class III (Fig. 7). Summary of water quality improvement within six weeks of FVI installation is shown in Table 2. 


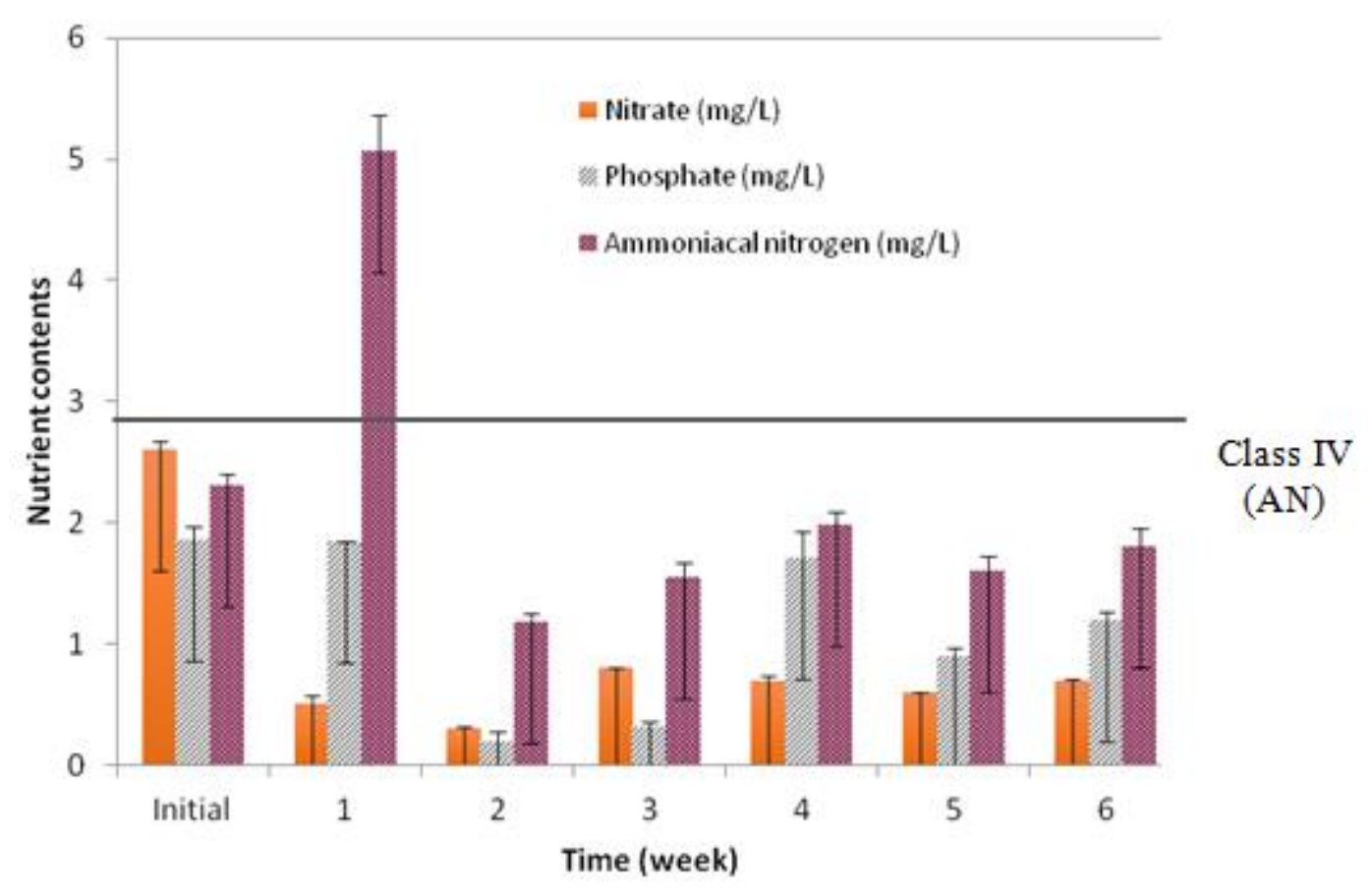

Figure 6. Weekly changes of nutrient contents in water after FVI installation

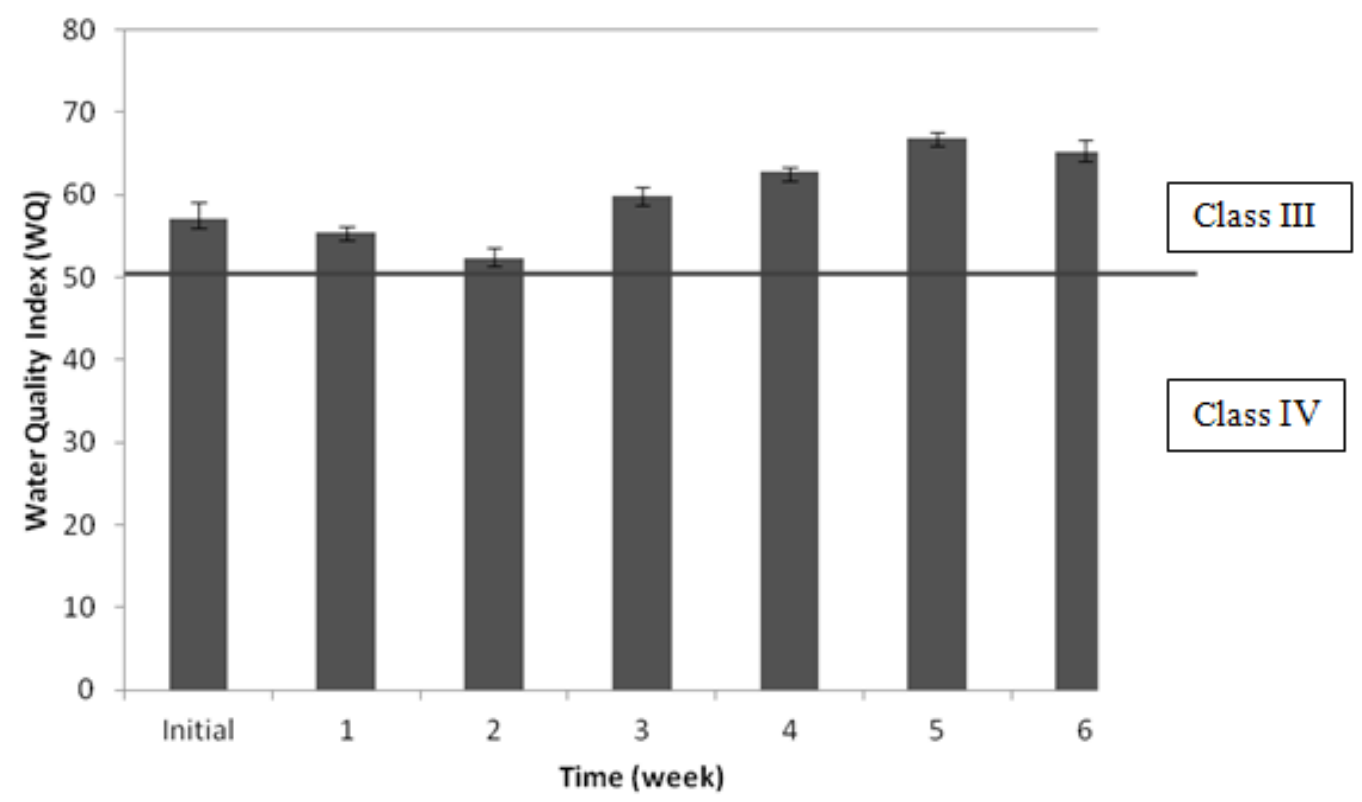

Figure 7. Water Quality Index (WQI) within six weeks of FVI installation

\section{Planting patterns}

In general, planting patterns of VG have significant effect on flow resistance across a FVI system. The different planting patterns showed that row planting is more suitable in a small river or stream rather than diamond planting due to more resistance during high flow (Metcalfe et al., 2003). However, this is only applicable for a river that receives 
relatively low flow of up to $0.1 \mathrm{~m}^{3} / \mathrm{s}$. Diamond planting was found to be easily flushed away especially during high flows and heavy rains. This was due to that diamond pattern has less resistance to high flow and was found to be in hydraulic retardance class B (Metcalfe et al., 2003). Therefore, three or more FVIs of similar size should be tied together to provide higher stability that can withstand higher flows.

Table 2. Summary of water quality improvement within six weeks of FVI installation

\begin{tabular}{c|c|c}
\hline Parameters (mg/L) & Initial & After six weeks \\
\hline Dissolved oxygen & 2.41 (Class III) & 4.63 (Class III) \\
Total suspended solids & 5.20 (Class I) & 3.80 (Class I) \\
Chemical oxygen demand & 41 (Class III) & 10 (Class I) \\
Nitrate & 2.60 & 0.70 \\
Phosphate & 1.86 & 1.20 \\
Ammoniacal nitrogen & 2.30 (Class IV) & 1.80 (Class IV) \\
Water quality index (WQI) & 57.00 (Class III) & 65.10 (Class III) \\
\hline
\end{tabular}

Flow rate: $0.06-0.07 \mathrm{~m} / 3 / \mathrm{s}$; treatment distance: $0.5 \mathrm{~km}$; river width: $3 \mathrm{~m}$; water depth: $0.5 \mathrm{~m}$; no. of pontoons: 9 (100 tillers each)

*pH remained at circum-neutral range; no improvement of BOD

\section{Implication for FVI treatment system design}

In order to calculate effective treatment system requirements (e. g. number of FVI and treatment distance), information on the given flow rate, initial and targeted pollutant concentration are required. The value of the targeted final concentration should have been agreed with relevant regulatory requirements. The estimation was based on the principle of a zero-order kinetics of pollutant removal (Kadlec and Wallace, 2009). Although it was known that some floating wetland treatment systems or AFIs follow a first-order kinetic model for pollutant removal (Wang and Sample, 2013), the model can result in overestimation of treatment system sizing (Kusin et al., 2012). Until further treatment system sizing is developed for floating wetland system, a zero-order kinetics can still predict the required treatment system requirements. According to the zero-order kinetic model, the treatment area required is a function of the pollutant concentration and flow rate divided by the removal rate. In this case the treatment 'area' is reflected by the number of floating island system (i. e. no. of pontoons) and treatment distance required. Notwithstanding the proposed design approach above, it is worth noting that when using a zero-order kinetic model several assumptions have been made such as pollutant removal is concentration-independent and under steady-state condition (Kadlec and Wallace, 2009). Even if first-order kinetics is to be adopted, the model on the other hand assumes a plug-flow system which is also rarely the case in real flowing water.

In this study, it is recommended that if the same degree of treatment is received as in the monitored site, a treatment distance of about $3.3 \mathrm{~km}$ along with 61 pontoons (FVIs) is required for the same river size in order to achieve a Class II river (i. e. minimum regulatory requirement) (Table 3). Whereas if a Class I river is intended, a treatment distance of $4.8 \mathrm{~km}$ is required and with 85 number of pontoons. Note that the estimation of treatment requirements for FVI system here is based on the calculated rates of 
pollutant removal in an earlier study (Suelee et al., 2017). A more comprehensive study on the rates of pollutant removal may determine the removal rates more accurately. By using this calculation guide, treatment requirements for other rivers of different sizes and flow rates may then be estimated, however it is subjected to the estimated rate of pollutant removal.

Table 3. Estimation of treatment requirements for FVI system

\begin{tabular}{c|c|c}
\hline Design criteria & Treatment requirement & Number of pontoon (FVI) \\
\hline For $0.1 \mathrm{~m}^{3} / \mathrm{s}$ flow & $\begin{array}{c}\text { Requires } 1500 \mathrm{~m}^{2} \\
\text { treatment 'area' or } 750 \mathrm{~m}^{3} \\
\text { of treatment volume }\end{array}$ & 9 (each of 100 no. of VGs) \\
\hline
\end{tabular}

To achieve Class II river;

(Example from the monitored site of the following characteristics):

\begin{tabular}{c|c|c|c}
\hline $\begin{array}{c}\text { Initial parameter } \\
\text { concentration }(\mathbf{m g} / \mathbf{L})\end{array}$ & $\begin{array}{c}\text { Target concentration } \\
(\mathbf{m g} / \mathbf{L})\end{array}$ & $\begin{array}{c}\text { *Treatment 'area' } \\
\text { required }\left(\mathbf{m}^{\mathbf{2}}\right)\end{array}$ & $\begin{array}{c}* \text { Treatment volume } \\
\text { required }\left(\mathbf{m}^{\mathbf{3}}\right)\end{array}$ \\
\hline $\mathrm{TSS}=5.2$ & Already Class I & - & - \\
\hline $\mathrm{BOD}=1.21$ & 1 & 74.11 & 37.06 \\
\hline $\mathrm{COD}=41$ & 25 & 705.88 & 352.94 \\
\hline $\mathrm{AN}=2.3$ & 0.3 & 9391.30 & 4695.65 \\
\hline & $\begin{array}{c}\text { Total treatment } \\
\text { 'area'/volume required }\end{array}$ & 10171.29 & 5085.65 \\
\hline & No. of pontoon required & 61 & \\
\hline To achieve Class I river; & $\begin{array}{c}\text { Treatment distance } \\
\text { required }\end{array}$ & $3.3 \mathrm{~km}$ & \\
\hline & $\begin{array}{c}\text { Total treatment 'area' } \\
\text { required }\end{array}$ & 14214.76 & \\
\hline & No. of pontoon required & 85 & \\
\hline & $\begin{array}{c}\text { Treatment distance } \\
\text { required }\end{array}$ & $4.8 \mathrm{~km}$ & \\
\hline
\end{tabular}

*Treatment requirements are calculated based on the estimated removal rates

\section{Field installation guide for FVI}

Specific installation guide for FVI presented here is only applicable for a relatively small river such as the aforementioned system. The river must be clear from invasive plants whilst rubbish/debris must be first trapped from the water flow to avoid damage to FVI and blockage of flow across the river at least $500 \mathrm{~m}$ from the FVI system. A concrete structure by the river side is preferable for easy FVI installation and must be provided at a point where flow is stable. FVI of $1 \mathrm{~m} \mathrm{x} 1 \mathrm{~m}$ planted with $100 \mathrm{VG}$ tillers can withstand water flow of up to $0.1 \mathrm{~m}^{3} / \mathrm{s}$. Non-rusting materials are preferable in the fabrication of FVI such as stainless steel clips, steel bar etc. VG must be planted on the FVI at young age so that the root grows while attaching to the net. VG shoot can be cut 
off prior to planting on the FVI to ensure that all tillers are at the same height. This is important to ensure FVI stability whilst the plants are growing on the system.

\section{Treatment system maintenance (vetiver grass pruning)}

The shoot of VG should be trimmed (pruning) at 2-month intervals to encourage the growth of the root for efficient pollutant uptake and to lengthen the life cycle of the vetiver grass. Proper pruning of the top crown enhances the efficiency of pollutant uptake by the vetiver system. Based on the observation in an earlier study (Suelee, 2015), pruning should be conducted regularly (e. g. 2-month intervals) by cutting the top crown specifically from the growth point when the plant grows up to 5-6 nodes or when the leaves grow about $50 \mathrm{~cm}$ long.

The reason why pruning enhances pollutant uptake by the plant is due to the fact that pruning can promote growing and tillering (Xia, 2003). It was found that as vetiver is a $\mathrm{C} 4$ plant (those which photosynthesise following the mechanism of $\mathrm{C} 4$ photosynthesis), it requires a large amount of sunshine for its growth and development. Adult vetiver of 150-160 $\mathrm{cm}$ high can form shading to the crown's stem and bed, therefore, proper pruning may lessen the shading density and heighten sunshine density in all parts of the plant, especially for improved photosynthesis of the new tillers. Pruning can effectively increase the leaf stomatal conductance and decrease the vapour pressure deficit at some degree, and helpful to the increase of net photosynthetic and transpiration rate (Yin et al., 2015). Xia (2003) suggested that pruning also cuts off pedicels or inhibits the plants from moving into the stage of reproductive growth, which would consume a great deal of water and nutrients owing to flowering and seeding. The old parts when cut off possibly produces stimulation to the plant itself, thus can also improve its growth and tillering.

\section{Long term monitoring}

Further monitoring of field FVI system installation can be carried out to observe the changes in water quality parameters at longer time and to evaluate on system design efficiency. This is also important to update on current rates of pollutant removal from such a treatment system. For acquiring more detailed understanding on the pollutant removal rates, the FVI technique can also be installed at other locations e. g. rivers of different flow rates, width and depth, and different ranges of water quality to observe on-site system efficiency more accurately. Monitoring of FVI system after cutting off their shoot at two-month intervals can be useful to observe the effect of plant growth and contaminant uptake.

\section{Conclusions}

Findings from field trial of the FVI system have shown that generally water quality is improved as indicated by $14 \%$ increase in WQI within six weeks of FVI installation in actual running water. Even though WQI remains at Class III, DO level has significantly increased whilst COD and nitrate were greatly removed. It has been proposed that treatment system performance of FVI can be reflected by the number of pontoons (FVIs) and treatment distance required to achieve desired water quality improvement. Note that also this treatment system design estimation is based on the calculated rates of pollutant removal. Further research may look into the estimation of the intended 
removal of pollutants more accurately. Despite this, field installation guide and treatment system maintenance have also been presented such that vetiver grass pruning is very important for medium- to long-term FVI performance.

Acknowledgements. The research was funded by the Humid Tropics Centre (HTC), Department of Irrigation and Drainage (DID), Malaysia. The authors would like to acknowledge Pakar Go Green Sdn. Bhd. for technical guidance and also the Environmental Forensics Research Centre (ENFORCE) Laboratory, Universiti Putra Malaysia for providing laboratory facilities. Special thanks are due to technical staffs of HTC and laboratory staffs of Faculty of Environmental Studies, Universiti Putra Malaysia for their assistance in completing the research.

\section{REFERENCES}

[1] Al-Badaii, F., Othman, M. S., Gasim, M. B. (2013): Water quality assessment of the Semenyih River, Selangor, Malaysia. - Journal of Chemistry 1-10. http://dx.doi.org/10.1155/2013/871056.

[2] American Public Health Association (APHA) (2005): Standard Methods for the Examination of Water and Wastewater. $19^{\text {th }}$ Ed. - American Water Works Association, Water Environment Federation, Washington DC.

[3] Ash, R., Truong, P. (2003): The use of vetiver grass wetland for sewerage treatment in Australia. - Third International Vetiver Conference, Guangzhou, China.

[4] Biswas, A. K., Tortajada, C. (2011): Water quality management: an introductory framework. - International Journal of Water Resources Development 27(1): 5-11.

[5] Chan, N. W. (2012): Managing urban rivers and water quality in Malaysia for sustainable water resources. - Water Resource Development 28(2): 343-354.

[6] Chang, Y. H., Wu, B. Y., Lai, C. F. (2015): A study of the ecological benefits of the green energy landscape fountain. - Ecological Engineering 75: 128-136.

[7] Cleophas, F. N., Isidore, F., Lee, K. H., Bidin, K. (2013): Water quality status of Liwagu River, Tambunan, Sabah, Malaysia. - Journal of Tropical Biology and Conservation 10: $67-73$.

[8] Danh, L. T., Truong, P., Mammucari, R., Tran, T., Foster, N. (2009): Vetiver grass, Vetiveria zizanioides: a choice plant for phytoremediation of heavy metals and organic wastes. - International Journal of Phytoremediation 11: 664-691.

[9] Darajeh, N., Idris, A., Truong, P., Aziz, A. A., Bakar, R. A., Man, H. C. (2014): Phytoremediation potential of vetiver system technology for improving the quality of palm oil mill effluent. - Advance Material Science and Engineering 1-10. http://dx.doi.org/10.1155/2014/683579.

[10] Department of Environment (DOE) (2010): Malaysia Environmental Quality Report 2010. - DOE, Putrajaya.

[11] Fulazzaky, M. A., Seong, T. W., Masrin, M. I. M. (2010): Assessment of water quality status for the Selangor River in Malaysia. - Water, Air and Soil Pollution 205: 63-77.

[12] Kadlec, R. H., Wallace, S. D. (2009): Treatment Wetlands. $2^{\text {nd }}$ ed. - CRC Press, Boca Raton, Florida.

[13] Kusin, F. M., Jarvis, A. P., Gandy, C. J. (2012): Hydraulic performance assessment of passive coal mine water treatment systems in the UK. - Ecological Engineering 49: 233243.

[14] Kusin, F. M., Jarvis, A. P., Gandy, C. J. (2014): Hydraulic performance and iron removal in wetlands and lagoons treating ferruginous coal mine waters. - Wetlands 34(3): 555564.

[15] Kusin, F. M., Zahar, M. Z. M., Muhammad, S. N., Mohamad, N. D., Madzin, Z., Sharif, S. M. (2016): Hybrid off-river augmentation system as an alternative raw water resource: 
the hydrogeochemistry of abandoned mining pond. - Environmental Earth Sciences 75: 230.

[16] Lu, H. L., Ku, C. R., Chang, Y. H. (2015): Water quality improvement with artificial floating islands. - Ecological Engineering 74: 371-375.

[17] Lynch, J., Fox, L. J., Owen Jr, J. S., Sample, D. J. (2015): Evaluation of commercial floating treatment wetland technologies for nutrient remediation of stormwater. Ecological Engineering 75: 61-69.

[18] Metcalfe, O., Truong, P., Smith, R. (2003): Hydraulic characteristics of vetiver hedges in deep flows. - Third International Vetiver Conference, Guangzhou, China.

[19] Othman, F., Eldin, M. E. A., Mohamed, I. (2012): Trend analysis of a tropical urban river water quality in Malaysia. - Journal of Environmental Monitoring 14: 3164-3173.

[20] Roongtanakiat, N., Tangruangkiat, S., Meesat, R. (2007): Utilization of vetiver grass (Vetiveria zizanioides) for removal of heavy metals from industrial wastewaters. Science Asia 33: 397-403.

[21] Shu, W. S. (2003): Exploring the potential utilization of vetiver in treating acid mine drainage (AMD). - Third International Vetiver Conference, Guangzhou, China.

[22] Shu, W., Xia, H. (2003): Integrated vetiver technique for remediation of heavy metal contamination: potential and practice. - Third International Vetiver Conference, Guangzhou, China.

[23] Shu, W. S., Xia, H. P., Zhang, Z. Q., Lan, C. Y., Wong, M. H. (2002): Use of vetiver and three other grasses for revegetation of $\mathrm{Pb} / \mathrm{Zn}$ Mine tailings: Field experiment. International Journal of Phytoremediation 4(1): 47-57.

[24] Suelee, A. L. (2015): Phytoremediation potential of vetiver grass (Vetiveria zizniodes) for water contaminated with selected heavy metal. - Bachelor Thesis, Universiti Putra Malaysia.

[25] Suelee, A. L., Hasan, S. N. M. S., Kusin, F. M., Mohamat-Yusuff, F., Ibrahim, Z. Z. (2017): Phytoremediation potential of vetiver grass for removal of heavy metalcontaminated water. - Water, Air \& Soil Pollution 228(4): 158.

[26] Truong, P. (2000): The global impact of vetiver grass technology on the environment. Second International Vetiver Conference, Thailand.

[27] Truong, P., Hart, B. (2001): Vetiver System for Wastewater Treatment. - Technical Bulletin no. 2001/21. Pacific Rim Vetiver Network. Office of the Royal Development Projects Board, Bangkok, Thailand.

[28] Truong, P., Smeal, C. (2003): Research, Development and Implementation of Vetiver System for Wastewater Treatment: GELITA Australia. - Technical Bulletin no. 2003/3. Pacific Rim Vetiver Network. Office of the Royal Development Projects Board, Bangkok, Thailand.

[29] Xia, H., Liu, S., Ao, H. (2000): A study on purification and uptake of garbage leachate by vetiver grass. - Second International Vetiver Conference, Thailand.

[30] Xia, H. P. (2003): Observations and experiments on the multiplication, cultivation and management of vetiver grass conducted in China in the 1950's. http://www.vetiver.com/CHN_propagation.html.

[31] Yao, K., Song, S., Zhang, Z., Xu, J., Zhang, R., Liu, J., Cheng, L., Liu, J. (2011): Vegetation characteristics and water purification by artificial floating island. - African Journal of Biotechnology 10(82): 19119-19125.

[32] Yeh, N., Yeh, P., Chang, Y. H. (2015): Artificial floating islands for environmental improvement. - Renewable and Sustainable Energy Reviews 47: 616-622.

[33] Yin, W., Chen, S., Sun, S., Xia, X., Liu, X. (2015): The effects of green pruning on growth the effects of green pruning on growth and physiological characteristics of poplar and physiological characteristics of poplar agroforestry system in China. - Beijing Forest University. 
[34] Zhang, L., Zhao, J., Cui, N., Dai, Y., Kong, L., Wu, J., Cheng, S. (2015): Enhancing the water purification efficiency of a floating treatment wetland using a biofilm carrier. Environmental Science and Pollution Research 1-7.

[35] Zhao, F., Yang, W., Zeng, Z., Li, H., Yang, X., He, Z., Gu, B., Rafiq, M. T., Peng, H. (2012): Nutrient removal efficiency and biomass production of different bioenergy plants in hypereutrophic water. - Biomass and Bioenergy 42: 212-218. 